\title{
Screening and treatment of immigrants and refugees to Canada for tuberculosis: Implications of the experience of Canada and other industrialized countries
}

\author{
ROGER E THOMAS MD PHD CCFP MRCGP, BRIAN GUSHULAK BSC MD
}

\begin{abstract}
RE Thomas, B GushulaK. Screening and treatment of immigrants and refugees to Canada for tuberculosis: Implications of the experience of Canada and other industrialized countries. Can J Infect Dis 1995;6(5):246-255.

ОвJестіve: To assess the incidence of tuberculosis in immigrants and refugees in Canada and other industrialized countries; the effectiveness of the screening process; the incidence of drug resistance; recommendations for prophylaxis and therapy; and indications for and effectiveness of directly observed therapy.

DATA Sources: MEDLINE search of literature published from 1985 to 1995 with the key words 'tuberculosis', 'Canada', 'screening', 'drug resistance', 'drug resistance, multiple', 'immigration and emigration', and the title words 'directly observed therapy'.

STUDY SELECTION: All studies reporting data on incidence, the outcomes of screening, drug resistance, therapy and directly observed therapy were selected.

DatA SYNTHESIS AND Conclusions: Data synthesis led to the conclusions that immigrants and refugees to Canada have five times the nonimmigrant and non-Aboriginal rate of tuberculosis; that screening programs discover new cases of tuberculosis on and after arrival and that up to $20 \%$ of those scheduled to attend a tuberculosis clinic after arrival may never attend; that drug resistance is widespread in countries from which Canada receives immigrants; and that directly observed therapy for active cases can result in $100 \%$ conversion rates.
\end{abstract}

Key Words: Directly observed therapy, Drug resistance, Immigration, Screening, Tuberculosis

Dépistage et traitement de la tuberculose chez les immigrants et réfugiés qui arrivent au Canada : expérience du Canada et d'autres pays industrialisés

ОвJестіF : Évaluer les répercussions de la tuberculose chez les immigrants et les réfugiés qui arrivent au Canada et dans d'autres pays industrialisés. L'efficacité du processus de dépistage, l'incidence de la résistance aux médicaments, les recommandations quant à la prophylaxie et au traitement et les indications, ainsi que l'efficacité d'un traitement observé directement sont présentés ici.

SOURCES DES DoNNÉES : Interrogation du réseau MEDLINE sur les articles publiés de 1985 à 1995, avec pour mots clés

voir page suivante

Elisabeth Bruyère Health Centre, University of Ottawa, and Quarantine Health Services, Laboratory Centre for Disease Control, Health Canada, Ottawa, Ontario

Correspondence: Dr RE Thomas, Elisabeth Bruyère Health Centre, 75 Bruyère Street, Ottawa, Ontario K1N 5C8. Telephone 613-241-3344, fax 613-241-1971

Received for publication January 9, 1995. Accepted June 13, 1995 


\begin{abstract}
«tuberculose», «Canada», «dépistage», «résistance médicamenteuse», «résistance médicamenteuse multiple», «immigration et émigration», et les mots titres «traitement directement observé».

SÉLECTION DES ÉtUdes : Toutes les études faisant état de données sur l'incidence, les résultats de dépistage, la résistance médicamenteuse, le traitement et le traitement directement observé ont été retenues.

Synthèse des Données et Conclusion : La synthèse des données mène à la conclusion que les immigrants et les réfugiés qui arrivent au Canada souffrent cinq fois plus de tuberculose que les non-immigrants et les non-aborigènes; que les programmes de dépistage découvrent de nouveaux cas de tuberculose à l'arrivée et après, que jusqu'à $20 \%$ des sujets attendus dans les cliniques de tuberculose après leur arrivée ne s'y présentent pas, que la résistance médicamenteuse est répandue dans les pays d'où arrivent les immigrants pour le Canada et que le traitement directement observé de cas actifs peut générer des taux de conversion de l'ordre de $100 \%$.
\end{abstract}

$\mathrm{T}$ HE PURPOSES OF THIS PAPER ARE TO ASSESS, FIRST, THE INCIdence of exposure to tuberculosis and the presence of active tuberculosis in immigrants and refugees in Canada and, second, in other industrialized countries; third, the effectiveness of the screening process for tuberculosis in immigrants and refugees in Canada; fourth, the incidence of drug resistance in immigrants; fifth, recommendations for prophylaxis and therapy and the complications of therapy; and finally, indications for and effectiveness of directly observed therapy (DOT).

A MEDLINE literature search for 1985 to 1995 was conducted using 'tuberculosis' and the medical subject headings 'Canada' (54 titles); 'immigration and emigration' (162 titles); 'drug resistance' and 'drug resistance, multiple' (66 titles); and the title words 'directly observed therapy' (10 titles).

\section{TUBERCULOSIS IN IMMIGRANTS AND REFUGEES IN CANADA}

Forty-two per cent of tuberculosis patients in Canada from 1985 to 1987 were born outside Canada (1). Immigrants have rates of tuberculosis five times higher than those of Canadians who are neither immigrants nor Aboriginal. From 1970 to 1990 , rates fell in immigrants of European origin but rose in those of Asian origin (2). In a study of 7028 immigrants in Montreal, $15 \%$ of those from countries with low rates of tuberculosis, $26 \%$ of those from intermediate countries, and $35 \%$ of those from countries with high rates were Mantoux-positive (defined as greater than $15 \mathrm{~mm}$ if they had been vaccinated with Bacille Calmette-Guérin, greater than $10 \mathrm{~mm}$ if not) (3).

Groups with significant tuberculosis rates other than immigrants are the aged ( $29 \%$ of cases are in those over 65 years of age), Aboriginals (17.5\% of cases) and the urban indigent. Fifty per cent of pediatric tuberculosis cases in Canada are Aboriginal children (4).

There has been a steady decline in rates in the Inuit (from $580 / 100,000$ population in $1970-72$, to $80 / 100,000$ in $1983-$ 89) and Status Indian populations (from 150/100,000 in $1970-72$, to $80 / 100,000$ in 1983-89) (1). Census divisions with rates over $20 / 100,000$ are all in northern Canada $(80 \%$ of which are in the Aboriginal population), and those with rates of 10 to $19 / 100,000$ are either in northern regions or in major metropolitan areas (with a disproportionate number of cases among the immigrant and Aboriginal populations).

In Canada, compared with the United States, there are relatively few patients who both have tuberculosis and are human immunodeficiency virus (HIV) positive. In British Colum- bia it is estimated that since the HIV epidemic began fewer than $2 \%$ of the active cases of tuberculosis have HIV-positive status (5). However, the relative risk of tuberculosis in a person who is HIV-positive is 400 times greater than the risk in the general Canadian population, and thus HIV status constitutes the most important risk factor for tuberculosis (6).

\section{TUBERCULOSIS IN IMMIGRANTS AND REFU- GEES IN OTHER INDUSTRIALIZED COUNTRIES}

In Canada, the United States, Australasia, Europe and Israel, immigrants have a considerable burden of latent tuberculosis with few clinical signs. The highest rates of clinical tuberculosis occur in immigrants from countries with high prevalence rates and in the first five years after immigration. However, higher rates persist even 20 to 40 years later in immigrants from countries with high prevalence rates $(7,8)$.

Australia has an immigrant population of similar origin to that of Canada. In a study of 2290 inner city schoolchildren in Sydney, $27.5 \%$ of the foreign-born had a positive Mantoux compared with $2 \%$ of Australian-born children (9). If the overseas-born arrived in Australia after they were 10 years of age, they were twice as likely to have a positive tuberculin test than if they were younger than 10 years on arrival. Immigrants to Australia born in Vietnam, Cambodia and the Philippines had tuberculosis rates between 100 and 400/100,000 compared with 1.5/100,000 for those born in Australia (10). The incidence of tuberculosis in those with AIDS was 1579/100,000.

In New Zealand, tuberculosis rates were 10 times higher in Pacific Islanders, 15 times higher in other immigrant groups and five times higher in Maoris than in those of European origin (11). The age of the immigrants was a key risk factor: compared with those aged 0 to 14 years, the rates in those 15 to 24 years were four times higher; in those 25 to 44 years six times higher; in those 45 to 64 years 12 times higher; and in those over 65 years 16 times higher.

In Europe, tuberculosis notifications steadily declined until 1985 , but since then have increased especially in drug-users, in HIV-positive patients and in recent immigrants from subSaharan Africa. In the Vaud canton of Switzerland 256 cases of tuberculosis were found by mass miniature $x$-ray testing among 50,784 immigrants: $1.4 \%$ of those from Africa, $1 \%$ from Turkey, $0.62 \%$ from the Middle East and $0.55 \%$ from Yugoslavia were diagnosed as needing prophylaxis (12). In a Belgian pediatric homecare centre $80 \%$ of the tuberculosis re- 
TABLE 1

Problems in screening for exposure to tuberculosis and case-finding in active tuberculosis

\section{Screening for exposure to tuberculosis}

Problem: Whom to screen

Solution: Pay meticulous attention in history-taking to risk factors (country of origin, exposed family member, alcoholism, HIV status, prior tuberculosis therapy), have a high suspicion for individuals with risk factors, take a careful history of past antituberculous medication, obtain a tuberculin test (and the two-step in nonreactors) and a chest $\mathrm{x}$-ray in any individual with any risk factors

\section{Case-finding of active tuberculosis}

Problem: Where to direct case-finding activities

Solution: Have a high suspicion for any individual with any risk factor or symptom, remembering that:

- Infection at any period of life confers a $10 \%$ lifetime risk of tuberculosis

- Although $85 \%$ present as pulmonary tuberculosis, immigrants are more likely to present with nonpulmonary sites

- Although most infants and children present with classic respiratory symptoms, fever and weight loss, most cases in immigrants are found by contact tracing

- Although $80 \%$ present with the symptoms of an active infection (cough, fever, malaise), $20 \%$ are asymptomatic

- The tuberculin test may be falsely negative in $20 \%$, especially in infants a few months of age, the elderly, those with advanced pulmonary disease, tuberculous serositis, those who are HIV-positive and other immunosuppressed patients

- The chest x-ray may be normal in $4 \%$, and $20 \%$ are atypical (especially in the HIV-positive)

- The sputum culture may be negative in $15 \%$

HIV Human immunodeficiency virus. Adapted from reference 6

ferrals were immigrants; $48 \%$ of the children who were symptomatic had an identifiable adult source (13). Tuberculosis rates among immigrants to the United Kingdom in 1988 were $135 / 100,000$ in Indians and 101/100,000 in Pakistanis and Bangladeshis compared with $4.7 / 100,000$ in the population born in the United Kingdom (14). Hindu females who migrate to the United Kingdom have rates of tuberculosis 5.5 times higher than Muslim females, and Hindu males 3.7 higher than Muslim males. One hypothesis to explain this is that the Hindu vegetarian diet reduces immunity (15). Particular concentrations of HIV-positive patients with tuberculosis have been noted: $12 \%$ of tuberculosis patients in Paris and $18 \%$ in a neighbouring Département were HIV-positive; $10 \%$ of AIDS patients in Frankfurt and Italy and $37 \%$ in Spain had tuberculosis (16). During the 1980s HIV emerged as the most effective promoter of tuberculosis, with rates of reactivation of $8 \%$ per year (17).

In the United States, tuberculosis is 13 times more prevalent among the immigrant population than among the nativeborn (18). In a study of illegal Mexican immigrants in Denver, $42 \%$ had Mantoux tests greater than $10 \mathrm{~mm}$, and $17 \%$ of the chest x-rays obtained showed old or current tuberculous infection (19). Immigrants to Seattle from Kampuchea and Laos had a 10-fold greater risk of having a positive sputum culture than other immigrants (20). Fifty-eight per cent of foreign-born students registering at the University of California at Los Angeles in 1988 had positive Mantoux reactions (21). The United States is a major reservoir of 10 to 15 million people with tuberculosis (22), with high concentrations among very disadvantaged groups: $50 \%$ of the homeless (23) and $18 \%$ of those living in shelters (24). These patients are a large highrisk group, but few can migrate to Canada from the United States, and immigrants from other parts of the world will therefore have a greater impact on Canada's tuberculosis rates.
Two per cent of Ethiopian immigrants to Israel had active tuberculosis (25).

Immigrants tend to have high rates of extrapulmonary disease (26). In one study in the United Kingdom 30\% of Asian dialysis patients presented with extrapulmonary tuberculosis, although they had lived in the United Kingdom, on average, for 15 years without any clinical signs of tuberculosis. Asian dialysis patients now routinely receive tuberculosis prophylaxis (27).

\section{THE EFFECTIVENESS OF THE SCREENING PROCESS FOR IMMIGRANTS AND REFUGEES}

The World Health Organization (WHO) estimates that 1.7 billion persons worldwide are or have been infected with tuberculosis, with each year 8 million new cases of active tuberculosis and 2.9 million deaths (28), and 100 million with drug-resistant strains (29). There are 3.1 million people who have tuberculosis and are HIV-positive (30). Tuberculosis control in Third World countries receives only two cents of every 10 dollars spent on health (29).

Screening for exposure to tuberculosis and the finding of active cases in both immigrants and refugees and the rest of the population depend on both an excellently organized national program, and the persistent application of history-taking and clinical skills of individual physicians. The key element in detection is an appropriate level of suspicion that the patient could be asymptomatically infected (Table 1).

The screening requirements of the Canadian immigration authorities include a full history, physical examination and laboratory investigations (Table 2). The Canadian Thoracic Society, the Canadian Lung Association, the Tuberculosis Directors of Canada and Health Canada suggest in addition a tuberculin test and cultures (Table 2).

Detailed evidence on how this surveillance and treatment system works is available for Manitoba, British Columbia and 
TABLE 2

Screening of immigrants to Canada for tuberculosis

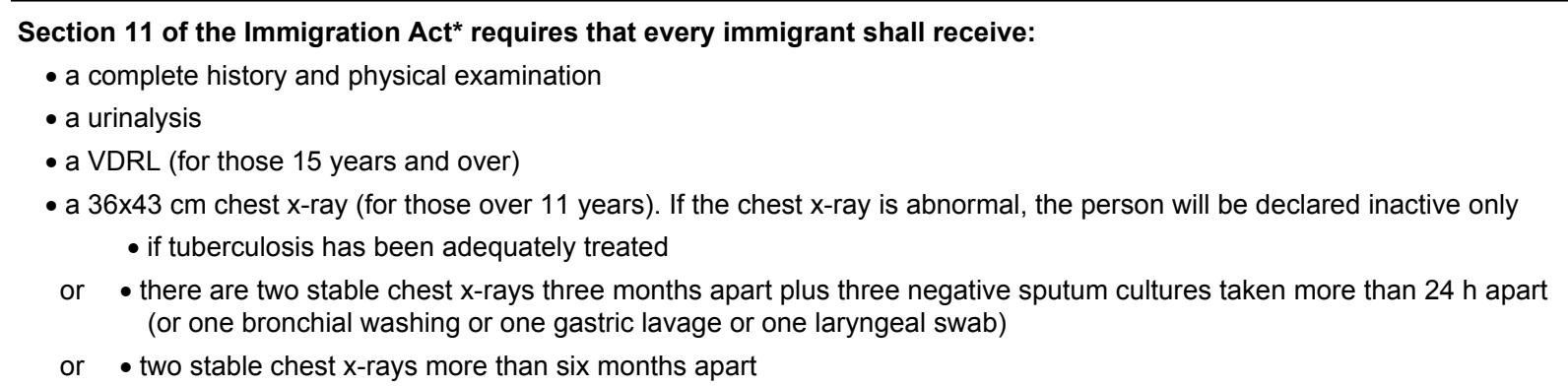

The Regulations approved by the Canadian Thoracic Society, the Canadian Lung Association, the Tuberculosis Directors of Canada and Health Canada ${ }^{\dagger}$

Newly arrived individuals with a previous history of tuberculosis or an abnormal chest x-ray suspicious of inactive tuberculosis ${ }^{\ddagger}$ should give:

- a complete history and physical examination

- a chest x-ray

- three sputum (or gastric lavage) specimens for smear and culture for Mycobacterium tuberculosis

- a tuberculin test

${ }^{*}$ Reference $84 ;{ }^{\dagger}$ Reference $85 ;{ }^{\ddagger}$ In 199212,000 immigrants had such an $x$-ray. VDRL Venereal Disease Research Laboratory test

Quebec. Between 1982 and 1985, 21,959 immigrants entered British Columbia from Asia (31). Before they emigrated, $1173(5.3 \%)$ had been judged to have inactive tuberculosis; on arrival in Canada 14 (1.5\% of the 932 who were examined) were found to have active tuberculosis, and a further seven developed active tuberculosis over the next four years $(0.33 \%$ per year, eight times the British Columbia rate). Ninety-four of the group examined in their country of origin and thought to have inactive tuberculosis either did not emigrate or landed in a province other than British Columbia, and 147 who landed did not comply with the mandatory screening program after arrival.

During 1979 to 1982,8692 Indochinese refugees emigrated to British Columbia, and the immigration service was aware of 21 cases of active tuberculosis before the immigrants entered Canada (32). Seventy-five more cases were discovered after entry: 28 in the first three months, four in the next three months, 16 in months seven to 12 , and 16 in months 12 to 24 of residence.

Of the immigrants admitted to Manitoba between 1981 and 1985, 523 (2.4\%) were placed under surveillance for tuberculosis, and their subsequent incidence of tuberculosis was 4.5 times higher than in those not placed under surveillance (33). Of the 429 who were seen at least once in the tuberculosis clinic, eight had had a positive culture in their country of origin, a further nine had a negative culture in their homeland but a positive culture in Canada, and one was not tested at home but was positive in Canada, for a total of 19 cases (5\%). Of the 483 immigrants scheduled to be seen in Winnipeg, 94 never attended, and 138 missed some clinic visits.

The experience of Manitoba and British Columbia shows that screening programs need to be able to locate and encourage cooperation in those who do not comply with screening after arrival, and to follow refugees for at least five years.

The detection of tuberculosis in immigrant children is es- pecially important, because their rates are higher than those in the native-born, they are likely to be asymptomatic, and the high initial mobility of immigrant children results in a large number of potential contacts with the attendant costs of following up entire schools. Childhood exposure to an active case gives a lifetime risk of tuberculosis reactivation of 5 to $10 \%$ (34). In a study of two schools in Montreal, $9.4 \%$ of foreign-born children, but only $0.4 \%$ of Canadian-born children, had a positive Mantoux test (35). In British Columbia during 1979 to 1988 there were 233 cases of tuberculosis in children up to the age of 15 (36). Only $40 \%$ of the 197 cases of primary pulmonary tuberculosis presented with symptoms (mainly cough and fever) and only 48 were diagnosed because they presented with symptoms. The remaining 154 were diagnosed as a result of tracing (mostly adult) contacts. Bacteriological studies were obtained in $83 \%$, and were positive in $22 \%$. Chest $x$-rays were available for $94 \%$, and lymphadenopathy was seen in $94 \%$ of these $x$-rays. The slowness of response to therapy and the diligence required in follow-up are demonstrated by the 125 patients with follow-up films: lymphadenopathy and consolidation worsened in 33\% despite three months of therapy. After six months of therapy only two had clear chest $x$-rays, most cleared by two years, but $7 \%$ still had abnormal chest $x$-rays three years later.

The majority of immigrants settle in the 10 major cities, and health care workers in these cities need to be sensitized to the numbers expected to be infected with tuberculosis and the need for screening.

Within the first year each case of active tuberculosis is estimated to transmit tuberculosis to 2 to $4 \%$ of their household contacts (37), but $37 \%$ of HIV-positive patients will develop tuberculosis within five months of exposure in their household (38-40). Each case of untreated active tuberculosis over a lifetime is estimated to infect between seven and 77 other individuals. 
The costs of screening 7573 illegal immigrants to Denver for tuberculosis were estimated at us $\$ 209,000$ (50\% for personnel costs and $41 \%$ for $x$-rays), yielding a cost for each patient who completed isoniazid therapy of $\$ 285$ (19).

When sputum samples (which cost $\$ 50$ to 75 ) were also collected in a study of 249 immigrants in Seattle with findings on two chest $\mathrm{x}$-rays consistent with pulmonary tuberculosis, only $5 \%$ of sputum cultures were found to be positive, and the cost per sputum-confirmed case of tuberculosis was us $\$ 1,996$ to 2,994 (20).

The costs of tracing the contacts of school children can be very high, partly because many students may be exposed to immigrants who tend to be mobile on first arrival in a new country. After a 10-year-old immigrant to Scarborough, Ontario, was noted to have active pulmonary tuberculosis, nine other family members were found to have markedly positive Mantoux reactions and chest x-ray changes compatible with tuberculosis, and were treated as having active tuberculosis. In the two schools involved, 722 children were screened with Mantoux tests: on first testing $7.1 \%$ (designated as $5 \mathrm{~mm}$ or greater if the child is in a class with an index case, or $10 \mathrm{~mm}$ or greater if not in such a class) and an additional $4.4 \%$ on second testing two to three months later had a positive Mantoux (35).

\section{DRUG RESISTANCE IN IMMIGRANTS AND REFUGEES}

Drug resistance can be systematically reduced if five requirements of appropriate therapy are achieved: prescribing an adequate regimen for the initial episode; testing for drug sensitivities; ensuring patient compliance; recognizing treatment failure (due mainly to resistance to isoniazid); and prescribing to overcome treatment failure (41).

Although HIV-positive patients are 20 times more likely to have other HIV-positive persons in their households, and HIV-positive patients have an $8 \%$ annual acquisition of tuberculosis, there does not yet appear to be an excess of drug resistance in such patients studied in Haiti, Zaire or the United States (42).

Short-course therapies of six months have become an important form of treatment. It is therefore of major concern that these therapies can have high rates of failure if offered to patients infected with Mycobacterium tuberculosis resistant to isoniazid and to rifampin (43). For example, only half of the patients in Denver with pulmonary tuberculosis resistant to both isoniazid and rifampin eventually had negative sputum cultures, even after prolonged individually tailored DOT with multidrug regimens, and $46 \%$ of those with treatment failure or relapse died (44).

In Manitoba from 1980 to 1989,1478 cases of active tuberculosis were diagnosed, specimens were cultured for 1392 , and $78 \%$ of these were positive (45). Seven per cent of these culture-positive cases were drug resistant. For immigrants in whom tuberculosis developed in their first year in Canada, the odds ratio of being resistant was 9.9 compared with other $\mathrm{Ca}$ nadians with tuberculosis. Ninety-one per cent of the drug resistance was to first line drugs (isoniazid and streptomycin).
Treaty Indians in Manitoba, however, had the same risk of resistance as the other patients born in Canada. In Manitoba $15 \%$ of culture-positive immigrants were resistant to one or more drugs compared with $4 \%$ of other patients (45).

In New York City during April 1991, 41\% of patients with positive tuberculosis cultures were HIV-positive, and prior antituberculosis therapy was the strongest factor predicting drug resistance to one or more drugs (odds ratio 2.7) or to isoniazid plus rifampin (odds ratio 5.3) (46). In patients who had not previously been treated, from 1955 to 1991 resistance to isoniazid increased from $3 \%$ to $15 \%$ and to streptomycin from $1 \%$ to $9 \%$; from 1978 to 1991 resistance to rifampin increased from $1 \%$ to $9 \%$ (46). By $1991,25 \%$ of the patients could transmit isoniazid-resistant organisms, and $20 \%$ could transmit organisms resistant to both isoniazid and rifampin. In a survey during 1991-92 of patients reported to the New York City Department of Health as having tuberculosis, $14 \%$ of both immigrant and American-born patients were reported as showing combined resistance to isoniazid and rifampin (47). In Santa Clara, California, $41 \%$ of immigrants were resistant to one or more drugs (48).

In Israel $37 \%$ of immigrants from Russia, $16 \%$ from Ethiopia and $12 \%$ of other patients were resistant to at least one drug (49).

There is considerable resistance to antituberculous drugs in countries from which Canada draws immigrants (Table 3). Among untreated patients there was resistance to at least one drug in $12 \%$ in Malawi (50), 15\% in Korea (51), 17\% in a sample of 10 Latin American countries (52), 20\% in both Gujarat, India (53) and Haiti (54), 27\% in Ghana (55) and 35\% in Turkey (56). Among treated patients $32 \%$ were resistant to at least one drug in Lahore, Pakistan (57), 41\% in Haiti (54) and $47 \%$ in Korea (51), and $56 \%$ were resistant to isoniazid in Gujarat (53). In a small study of gene mutations in $M$ tuberculosis at the Pitié-Salpétrière Hospital in Paris, of the 11 untreated non-European immigrants $55 \%$ were resistant to rifampin, $64 \%$ to streptomycin and $100 \%$ to isoniazid, all by known gene mutations (58), but at Mount Sinai Hospital in New York City immigrants from the Third World were less likely to be multiple-drug resistant than other patients (59). In Rio de Janeiro $8 \%$ of the contacts of multiple-drug resistant patients contracted tuberculosis within a two-year period, with $50 \%$ acquiring tuberculosis with the same multiple resistance pattern, $10 \%$ a different multiple-drug resistant pattern, and $40 \%$ with susceptible organisms, showing that tuberculosis can be acquired from multiple sources, even in those living with an index case (60).

Particularly troubling is the finding that resistance in some developing countries is higher among young people (who are more likely to migrate). In Korea initial drug resistance was found in $32 \%$ of patients with tuberculosis under 30 years of age and $14 \%$ in those over 59 (51). Similarly in the United States, $22 \%$ of children under 15 and $9 \%$ of patients over 65 with tuberculosis were resistant (61).

From the 1960s to the 1980s rates of resistance worldwide were highest in those Asian countries with intermediate development levels sufficient to permit medications to be readily 
TABLE 3

Percentage resistance to antituberculous drugs in selected countries of emigration to Canada

\begin{tabular}{|c|c|c|c|c|c|c|c|c|c|c|c|c|c|c|c|c|c|c|c|c|}
\hline \multirow{3}{*}{ Location } & \multicolumn{10}{|c|}{ No prior therapy } & \multicolumn{10}{|c|}{ Prior therapy } \\
\hline & \multicolumn{5}{|c|}{ Number of drugs } & \multicolumn{5}{|c|}{ Specific drugs } & \multicolumn{5}{|c|}{ Number of drugs } & \multicolumn{5}{|c|}{ Specific drugs } \\
\hline & $\geq 1$ & 1 & 2 & 3 & 4 & TO & INH & $\mathbf{R I}$ & ST & ET & $\geq 1$ & 1 & 2 & 3 & 4 & TO & INH & $\mathbf{R I}$ & ST & ET \\
\hline India & 20 & 14 & 5 & 1 & & & 14 & 0 & 7 & 4 & & & & & & & 56 & 37 & 27 & \\
\hline Ghana & & & & & & & 27 & 0 & 23 & 0 & & & & & & & & & & \\
\hline Malawi & 12 & & & & & 5 & 4 & 1 & 4 & 0 & & & & & & & & & & \\
\hline Latin America & 17 & 12 & 3 & 1 & & 17 & 7 & 1 & 12 & 0.4 & & & & & & & & & & \\
\hline \multirow[t]{2}{*}{ Korea } & 15 & & & 5 & & & 13 & & 7 & 2 & 47 & & & 13 & & & 42 & 15 & 19 & 11 \\
\hline & \multicolumn{10}{|c|}{$\%$ Initially resistant to } & \multicolumn{10}{|c|}{$\%$ Acquired resistance to } \\
\hline Turkey & 35 & 16 & 8 & 1 & 1 & 27 & 5 & 11 & 21 & 4 & 53 & 19 & 19 & 10 & 6 & 53 & 30 & 36 & & \\
\hline \multicolumn{21}{|c|}{$\begin{array}{l}\text { ET Ethambutol; INH Isoniazid; RI Rifampin; ST Streptomycin; TO Total. Pakistan (reference 57; } 256 \text { culture + patients, Mayo Hospital and Lahore General Hospital, La- } \\
\text { hore); India (reference 53; } 570 \text { samples from KJ Mehta Tuberculosis Hospital, Armagadh, 1983-86); Ghana (reference 55; } 99 \text { patients, Agogo Hospital, 1985-87); Ma- } \\
\text { lawi (reference 50; } 373 \text { patients, Karonga Lepra Evaluation Project, 1986-93); Kenya (reference 86; } 374 \text { adults presenting with first case of suspected tuberculosis to } \\
\text { Infectious Diseases Hospital or Ngaira Avenue Chest Clinic, Nairobi. Resistance in HIV-positive cases was 7.5\% for INH, 1\% for ST); Haiti (reference 54; } 268 \text { patients, } \\
\text { Hôpital Albert Schweitzer, Deschapelles, 1988); Latin America (reference 52; } 30 \text { clusters each of } 35 \text { smear-positive patients detected in tuberculosis control programs } \\
\text { during "the second half of the 1980s to the early } 1990 \text { s" in Argentina, Bolivia, Brazil, Chile, Colombia, Cuba, Haiti, Mexico, Paraguay and Peru); Korea (reference 51; } \\
127 \text { new and } 62 \text { previously treated cases in the } 1990 \text { nationwide tuberculosis prevalence survey); Turkey (reference 56; } 785 \text { patients, Sureyyapasa Center, Istanbul, } \\
\text { 1992) }\end{array}$} \\
\hline
\end{tabular}

available but without health care systems well financed enough to ensure regularly supervised administration (62). However, a poor country such as Tanzania, through an excellent national program, has maintained initial rifampin resistance below $1 \%$ for the past 15 years, despite the HIV epidemic; Korea and Algeria also have well-run national control programs (61).

\section{RECOMMENDATIONS FOR PROPHYLAXIS AND THERAPY, AND COMPLICATIONS OF THERAPY}

The effectiveness of isoniazid prophylaxis has been confirmed by randomized controlled trials, with maximum benefit occurring after 12 months, although compliance is better with six months' prophylaxis (6). Patients with only an abnormal tuberculin test should be given prophylaxis for six months, those with a stable abnormal radiograph consistent with previous tuberculosis for 12 months, and those with HIV for 24 months (63). Nine months' prophylaxis is recommended for children (64).

After reviewing the world literature on drug resistance from the 1960s onwards, Iseman and Sbarbaro (62) concluded that, for a patient without apparent risk factors for resistance, a three-drug regimen of isoniazid, rifampin and ethambutol is indicated, and for patients from an area with a high prevalence of resistance, a four-drug regimen of isoniazid, rifampin, pyrazinamide and ethambutol is indicated. For patients with a history of prior chemotherapy or who are epidemiologically at risk for resistance, a five-drug regimen including three drugs to which the patient had not previously been exposed should be used.

The Centers for Disease Control and Prevention in Atlanta, Georgia (65), based on experience with drug resistance in the United States (Tables 4,5), recommends a four-drug regimen (isoniazid, rifampin, pyrazinamide, and streptomycin or ethambutol) for the first two months, until drug susceptibilities are known. This would ensure that $95 \%$ of patients would be treated with a regimen that includes two drugs to which they are sensitive. Sputum conversion is also accomplished faster than with a three-drug regimen. A patient who defaults on the four-drug regimen is also more likely to be cured and not relapse when treated for the same duration as a patient receiving three-drug therapy.

Careful discussion of potential side effects and the benefits of therapy is essential to avoid discontinuance of therapy.

\section{THE EFFECTIVENESS OF AND INDICATIONS FOR DOT}

Studies using DOT with a patient-centred approach, training of the health team to be sensitive to patients' needs, social service assistance and thorough case management of therapy have been shown to be $100 \%$ effective in treating tuberculosis, and all other methods are ineffective compared with this gold standard (66).

A study in California that did not use DOT did use several patient-centred approaches: the educators spoke Korean and Spanish; the taking of medications was linked with other activities; and ways to remember medications and future appointments and test results were recorded in a booklet (67). At each visit questions were answered, misunderstandings were explained, and tailored education messages based on the initial interview and subsequent assessments, educational reinforcement about tuberculosis, enlistment of support from family and friends, and contracting were used. Among patients with active tuberculosis adherence to the medication regimen improved from $57 \%$ with usual care to $71 \%$, and for patients receiving prophylactic treatment adherence improved from $14 \%$ with usual care to $42 \%$, but these results are not as good as in studies that used DOT. 


\section{TABLE 4}

\section{Initial treatment regimen options for children and adults}

Option 1 Isoniazid, rifampin, pyrazinamide, ethambutol or streptomycin daily for eight weeks. Stop ethambutol or streptomycin when sensitivity to isoniazid and rifampin is demonstrated

Then isoniazid plus rifampin daily (or two to three per week by DOT) for 16 weeks in areas where isoniazid resistance not documented $\leq 4 \%$

Total treatment duration should be six months AND three months beyond culture conversion to negative*

Option 2 DOT of isoniazid, rifampin, pyrazinamide, ethambutol or streptomycin daily for two weeks, then twice a week for six weeks Then isoniazid plus rifampin twice a week for 16 weeks by DOT

Option 3 DOT of isoniazid, rifampin, pyrazinamide, ethambutol or streptomycin for six months ${ }^{\dagger}$

HIV-positive status: Options 1, 2 or 3 can be used, but should be continued for nine months AND at least six months beyond culture converson to negative

Pregnancy: Neither streptomycin (may cause congenital deafness) nor pyrazinamide (absence of teratogenicity has not been demonstrated) should be used. The regimen is for nine months, and until drug susceptibilities are known, the preferred initial regimen is isoniazid, rifampin and ethambutol

Lactation: Isoniazid, rifampin and ethambutol are safe because the concentrations passed into breast milk are very low.

Conversely, breast feeding while taking these drugs confers no protection on the baby

If the patient is clinically, smear- or culture-positive after three months: a tuberculosis medical expert should be consulted

DOT Directly observed therapy; HIV Human immunodeficiency virus. *The American Academy of Pediatrics (reference 64) recommends option 1, and in the case of bone, joint, miliary or meningitic tuberculosis, 10 months of isoniazid and rifampin; ${ }^{\dagger}$ The strongest evidence from clinical trials is the effectiveness of all four drugs administered for the full six months. There is weaker evidence that streptomycin can be discontinued after four months if the isolate is susceptible to all drugs. The evidence for stopping pyrazinamide before the end of six months is equivocal for the thrice/week regimen, and there is no evidence of the effectiveness of this regimen with ethambutol for less than the full six months. Data from reference 65

The Korean National Tuberculosis Program in 1989 without using DOT achieved $96 \%$ efficacy (conversion in those completing isoniazid/rifampin/ethambutol) and $80 \%$ efficiency (conversion in those starting isoniazid/ rifampin/ethambutol) through excellent organization, careful monitoring of resistance and shorter treatment regimens (51).

A study of illegal aliens in Denver who had been screened for tuberculosis linked adherence to medications with subsequent acquisition of legal immigrant status, and obtained $70 \%$ adherence to therapy (19).

Studies that used small financial incentives (68) or telephone reminders with personal contact after a failed appointment showed minimal effects (69).

The effects of introducing DOT were assessed in a retrospective review of all patients with positive $M$ tuberculosis cultures in Tarrant County Health Department, Texas (70). A period of six years of unsupervised therapy was followed by a period of six years of DOT with isoniazid, rifampin and pyrazinamide (plus ethambutol or streptomycin or capreomycin until isolates were confirmed to be fully sensitive to the first three drugs). There was a dramatic reduction in primary resistance from $13.0 \%$ to $0 \%$, in acquired resistance from $10.3 \%$ to $0 \%$, in multidrug resistance from $6.1 \%$ to $0 \%$ and in relapse from $20.9 \%$ to $0 \%$. During DOT, medications were administered under observation Monday through Friday for the first two to four weeks of therapy, and then twice weekly for the next six months. About $30 \%$ of the patients in both treatment periods had a history of alcohol abuse.

In Denver in another population with a high $(57 \%)$ incidence of alcohol abuse, DOT was given with isoniazid, rifampin, pyrazinamide and streptomycin given daily for two weeks, then in high doses twice weekly for another six weeks followed by isoniazid and rifampin twice weekly for another 18 weeks (71). Thirteen of the 160 patients were lost to follow-up (mostly because they moved out of Denver) and four died. In the remainder there were no treatment failures and only two relapses (both of them alcoholics who became culturenegative after four weeks of therapy but then missed some appointments). In patients with pulmonary tuberculosis, sputum cultures became negative after a median of 4.6 weeks, and $100 \%$ by 20 weeks.

Studies of intermittent DOT (thrice-weekly therapy for the entire treatment period) in Hong Kong (72), (thrice-weekly therapy for three months followed by twice-weekly therapy for three months) in Madras (73), and in Romania (74) are as effective as programs that begin with daily observed therapy for the first two to four weeks.

In contrast, in a self-administered regimen planned to last six months, $39 \%$ of the patients dropped out of the study, and in a nine-month regimen $49 \%$ dropped out (75). The cost of the six-month regimen was us $\$ 327$ per patient, whereas the Denver DOT regimen cost US $\$ 397$ per patient but could be reduced to us $\$ 283$ if two chest $x$-rays and two cultures were deleted, by relying on the greater efficacy of DOT (76). In New York City only $11 \%$ of the tuberculosis patients discharged from one hospital followed up in clinic (77), but therapy completion rates of up to $98 \%$ are experienced when DOT is used (78).

Noncompliance can be expected to occur in patients with psychiatric illness, alcoholism, drug addiction or who are homeless (66), but cannot be predicted on the basis of age, sex, socioeconomic status or estimates by health personnel (79). Interviews with intravenous drug users in Brooklyn, New York showed that DOT is appropriate because many of them had little knowledge about tuberculosis or their own tuberculosis status, and were afraid of detention for tuberculosis and 
TABLE 5

Dosage recommendations for the initial treatment of tuberculosis in children and adults

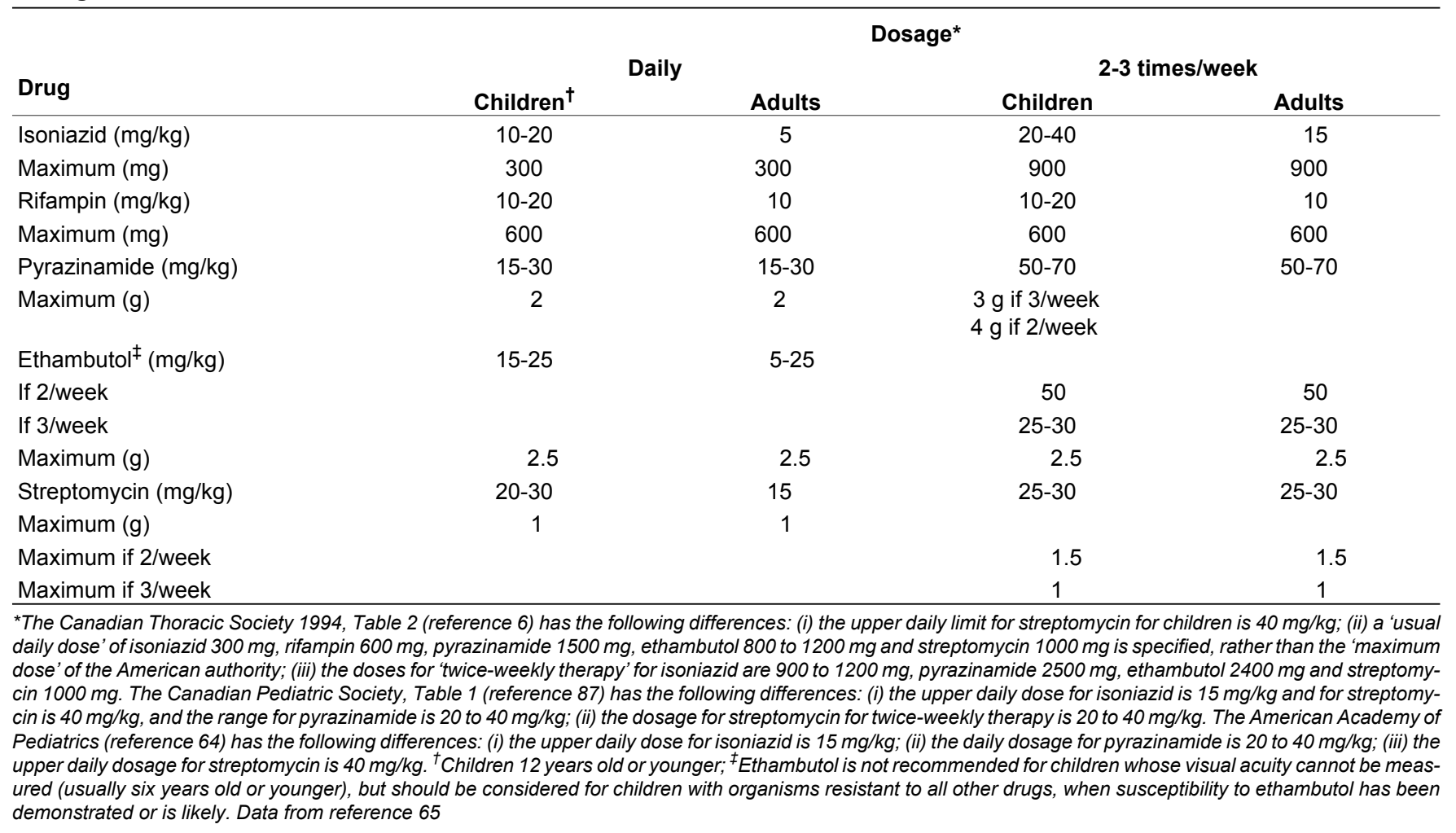

therefore stopped treatment (80). Completion rates for therapy in one study of homeless patients in the United States improved from $44 \%$ to $89 \%$ when the provision of shelter and food vouchers was added to DOT (81). (There has been no research on reactivation rates if free housing is discontinued once the patient has completed treatment.)

The four essential aspects of DOT are that therapy should be highly patient-centred (the patient should experience no barriers to receiving therapy), resistance should be carefully monitored and treated, a monitoring and information system should be meticulously maintained, and therapy cannot be delegated by the DOT worker to a family member because that person may connive with the patient or be under pressure from the patient not to complete the therapy (eg, a child repeatedly spits out the tuberculosis medications) (82).

Options for control other than DOT are treatment of all known active tuberculosis cases in the home country for six months before immigration (the current Australian policy); a payment on completion of therapy to new arrivals who need prophylaxis (on the model of the $\$ 1,000$ payment in France for completion of antenatal care); or requiring new arrivals to post a bond, which would be repaid plus interest on completion of therapy, but these are less likely to ensure completion of therapy.

\section{CONCLUSIONS}

Exposure to tuberculosis is widespread among immigrants to Canada. Active tuberculosis is most likely to develop in immigrants from countries with a high prevalence and during the first five years in Canada, but risks remain higher over the following 40 years than they do for the population born in Canada.

Canada is not optimally organized to detect and follow patients who are at risk for developing tuberculosis because Canada has no national reference centre to track movement between provinces, and there is separation of the responsibility for surveillance (Laboratory Centre for Disease Control) from that for treatment (physicians and public health departments).

DOT should be instituted for each active case of tuberculosis, and the name of each patient continuing or completing therapy should be circulated at the beginning of each month to treating physicians and public health departments, permitting prompt reinstitution of DOT by public health departments in those patients who discontinue therapy (83).

\section{REFERENCES}

1. Brancker A, Enarson DA, Grzybowski S, Hershfield ES, Jeanes CWL. A statistical chronicle of tuberculosis in Canada: Part II. Risk today and control. Health Rep 1992;4:277-92.

2. Gaudette LA, Ellis E. Tuberculosis in Canada: a focal disease requiring distinct control strategies for different risk groups. Tuber Lung Dis 1993;74:244-53.

3. Menzies R, Vissandjee B, Amyot D. Factors associated with tuberculin reactivity among the foreign-born in Montreal. Am Rev Respir Dis 1992;146:752-6.

4. FitzGerald JM, Pineda R, Branckner A. The epidemiologic pattern of pediatric tuberculosis (TB) in Canada: a report of 1,822 cases diagnosed between 1979-89. Am Rev Respir Dis 1992;145 (Suppl 2):145.A106.

5. Korzeniewska-Kosela M, Fitzgerald JM, Vedal S, et al. Spectrum of 
tuberculosis in patients with HIV infection in British Columbia: report of 40 cases. Can Med Assoc J 1992;146:1927-34.

6. Canadian Thoracic Society, Tuberculosis Committee. Essentials of tuberculosis control for the practising physician. Can Med Assoc J 1994;150:1561-71.

7. Enarsen DA, Sjogren I, Grzybowski S. Incidence of tuberculosis among Scandinavian immigrants in Canada. Eur J Respir Dis 1980;61:139-42.

8. British Medical Research Council Tuberculosis and Chest Diseases Unit National Survey on notifications of tuberculosis in England and Wales in 1983. BMJ 1985;291:658-61.

9. Alperstein G, Fett MJ, Reznik R, Thomas M, Senthil M. The prevalence of tuberculosis among year 8 schoolchildren in inner Sydney in 1992. Med J Aust 1994;160:197-201.

10. Maclntyre CR, Dwyer B, Streeton JA. The epidemiology of tuberculosis in Victoria. Med J Aust 1993;159:672-7.

11. Stehr-Green JK. Tuberculosis in New Zealand, 1985-90. NZ Med J 1992;105:301-3.

12. Bonvin L, Zellweger JP. Mass miniature x-ray screening for tuberculosis among immigrants entering Switzerland. Tuber Lung Dis 1992;73:322-5.

13. Toppet M, Malfroot A, Hofman B, Casimir G, Cantraine F, Dab I. Tuberculosis in children: a 13-year follow up of 1714 patients in a Belgian home care centre. Eur J Pediatr 1991;150:331-5.

14. Ormerod LP, Shaw RJ, Mitchell DM. Tuberculosis in the UK, 1994: current issues and future trends. Thorax 1994;49:1085-9.

15. Finch PJ, Millard FJ, Maxwell JD. Risk of tuberculosis in immigrant Asians: culturally acquired immunodeficiency? Thorax 1991;46:1-5.

16. Raviglione MC, Sudre P, Rieder HL, Spinaci S, Kochi A. Secular trends of tuberculosis in Western Europe. Bull World Health Organ 1993;71:297-306.

17. Selwyn PA, Hartel D, Lewis VA, et al. A prospective study of the risk of tuberculosis among intravenous drug users with human immunodeficiency virus infection. N Engl J Med 1989;320:545-50.

18. Iralu JV, Maguire JH. Pulmonary infections in immigrants and refugees. Semin Infect Dis 1991;6:235-46.

19. Blum RN, Polish LB, Tapy JM, Catlin BJ, Cohn DL. Results of screening for tuberculosis in foreign-born persons applying for adjustment of immigration status. Chest 1993;103:1670-4.

20. Nolan CM, Teklu B, Wu R. The use of sputum cultures in the evaluation of immigrants classified as tuberculosis suspects. Am Rev Respir Dis 1989;140:996-1000.

21. Quillan S, Malotte CK, Shlian D. Evaluation of a tuberculosis screening and prophylaxis program for international students. J Am Coll Health 1990;38:165-70.

22. Centers for Disease Control. The use of preventive therapy for tuberculous infection in the United States: recommendations of the Advisory Committee for Elimination of Tuberculosis. MMWR 1990;39:9-12.

23. Schiffelbein CW Jr, Snider DE Jr. Tuberculosis control among homeless populations. JAMA 1988;148:1843-6.

24. Torres RA, Mani S, Altholz J, Brickner PW. Human immunodeficiency virus infection among homeless men in a New York City shelter. Association with Mycobacterium tuberculosis infection. Arch Intern Med 1990;150:2030-6.

25. Wartski SA. Tuberculosis in Ethiopian immigrants Isr J Med Sci 1991:27:288-92.

26. Nisar M, Williams CS, Davies PD. Experience of tuberculosis in immigrants from South East Asia - implications for the imminent lease back of Hong Kong. Respir Med 1991;85:219-22.

27. Kwan JT, Hart PD, Raftery MJ, Cunningham J, Marsh FP. Mycobacterial infection is an important infective complication in British Asian dialysis patients. J Hosp Infect 1991;19:249-55.

28. Arachi A. The global tuberculosis situation and the new control strategy of the World Health Organization. Tubercle 1991;72:1-6.

29. World Health Organization. Press Release WHO/23, 20 March 1995.

30. Murray JF. Tuberculosis and human immunodeficiency virus infection during the 1990's. Bull Int Union Tuberc Lung Dis 1991;66:21-5.

31. Wang J-S, Allen EA, Enarson DA, Grzybowski S. Tuberculosis in recent Asian immigrants to British Columbia, Canada: 1982-1985. Tubercle 1991:72:277-83.

32. Enarson DA. Active tuberculosis in Indochinese refugees in British Columbia. Can Med Assoc J 1984;131:39-42.

33. Orr PH, Manfreda J, Hershfield ES. Tuberculosis surveillance in immigrants to Manitoba. Can Med Assoc J 1990;142:453-8.

34. Rieder HL, Cauthen GM, Comstock GW, Snider DE Jr. Epidemiology of tuberculosis in the United States. Epidemiol Rev 1989;11:79-98.

35. Rothman LM, Dubeski G. School contact tracing following a cluster of tuberculosis cases in two Scarborough schools. Can J Public Health 1993;84:297-302.

36. Pineda R, Leung A, Muller NL, et al. Intrathoracic pediatric tuberculosis: a report of 202 cases. Tuber Lung Dis 1993;74:261-6

37. Bailey WC, Albert RK, Davidson PT, et al. Treatment of tuberculosis and other mycobacterial diseases: an official statement of the American Thoracic Society. Am Rev Respir Dis 1983;127:790-6.

38. Centers for Disease Control. Nosocomial transmission of multidrug-resistant tuberculosis among HIV-infected persons - Florida and New York, 1988-1991. MMWR 1991;40:585-91.

39. Daley CL, Small PM, Schecter GF, et al. An outbreak of tuberculosis with accelerated progression among persons infected with the human immunodeficiency virus. An analysis using restriction-fragment-lengthpolymorphisms. N Engl J Med 1992;326:231-5.

40. Dooley SW, Villarino ME, Lawrence M, et al. Nosocomial transmission of tuberculosis in a hospital unit for HIV-infected patients. JAMA 1991;267:2632-5

41. O'Brien RJ. Drug-resistant tuberculosis: etiology, management and prevention. Semin Respir Infect 1994;9:104-12.

42. Nunn $P$, Felten $M$. Surveillance of resistance to antituberculosis drugs in developing countries. Tuberc Lung Dis 1994;75:163-7.

43. Valenzuela P, Valenzuela MT, Ponce J. Response to short-course chemotherapy of patients with initial resistance to anti-tuberculosis drugs. Bull Pan Am Health Organ 1988;22:175-83

44. Goble M, Iseman MD, Madsen LA, Waite D, Ackerson L, Horsburgh CR Jr. Treatment of 171 patients with pulmonary tuberculosis resistant to isoniazid and rifampin. N Engl J Med 1993;328:527-32.

45. Long R, Manfreda J, Mendella L, Wolfe J, Parker S, Hershfield E. Antituberculous drug resistance in Manitoba from 1980 to 1989. Can Med Assoc J 1993;148:1489-95.

46. Frieden TR, Sterling T, Pablos-Mendez A, Kilburn JO, Cauthen GM, Dooley SW. The emergence of drug-resistant tuberculosis in New York City. N Engl J Med 1993;328:521-6.

47. Driver $C R$, Frieden $T R$, Bloch $A B$, Onorato IM. Drug resistance among tuberculosis patients, New York City, 1991 and 1992. Public Health Rep 1994;109:622-6.

48. Riley LW, Arathoon E, Loverde VD. The epidemiologic patterns of drug-resistant Mycobacterium tuberculosis infections: A community-based study. Am Rev Respir Dise 1988;139:1282-5.

49. Lavy A, Mates A. A 10 year survey on Mycobacterium tuberculosis isolates in Israel and their drug resistance. Isr J Med Sci 1994;30:805-10.

50. Glynn JR, Jenkins PA, Fine PEM, et al. Patterns of initial and acquired anti-tuberculous drug resistance in Karonga District, Malawi. Lancet 1995;345:907-10

51. Kim SJ, Hong YP. Drug resistance of Mycobacterium tuberculosis in Korea. Tuberc Lung Dis 1992;73:219-24.

52. Laszlo A, de Kantor IN. A random sample survey of initial drug resistance among tuberculosis cases in Latin America. Bull World Health Organ 1994;72:603-10.

53. Trivedi SS, Desai SG. Primary antituberculosis drug resistance and acquired rifampicin resistance in Gujarat, India. Tuberc Lung Dis 1988;69:37-42.

54. Scalcini M, Carre G, Jean-Baptiste M, et al. Antituberculous drug resistance in Central Haiti. Am Rev Respir Dis 1990;142:508-11.

55. van der Werf TS, Groothuis DG, van Klingeren B. High initial drug resistance in pulmonary tuberculosis in Ghana. Tuberc Lung Dis 1989;70;249-56.

56. Tahaoglu K, Kizkin O, Karagoz T, et al. High initial and acquired drug resistance in pulmonary tuberculosis in Turkey. Tuberc Lung Dis 1994; 75:324-8.

57. Aziz A, Siddiqi SH, Aziz K, Ishaq M. Drug resistance of Mycobacterium tuberculosis isolated from treated patients in Pakistan. Tuberc Lung Dis 1989;70:45-51.

58. Heym B, Honore N, Truffot-Pernot C, et al. Implications of multidrug resistance for the future of short-course chemotherapy of tuberculosis: a molecular study. Lancet 1994;344:293-8.

59. Weltman AC, Rose DN. Tuberculosis susceptibility patterns, predictors of multidrug resistance, and implications for initial therapeutic regimens at a New York City Hospital. Arch Intern Med 1994;154:2161-7.

60. Jacobs RF. Multiple-drug-resistant tuberculosis. Clin Infect Dis 1994;19:1-10.

61. Rieder HL. Drug-resistant tuberculosis: issues in epidemiology and challenges for public health. Tuberc Lung Dis 1993;75:321-3.

62. Iseman MD, Sbarbaro JA. The increasing prevalence of resistance to antituberculosis chemotherapeutic agents: implications for global tuberculosis control. Curr Clin Topics Infect Dis 1992;12:188-207.

63. Levin AC, Gums JG, Grauer K. Tuberculosis: the primary care physician's role in eradication. Postgrad Med 1993;93:46-58.

64. American Academy of Pediatrics. Chemotherapy for tuberculosis in infants and children. Pediatrics 1992;89:161-5.

65. Centers for Disease Control and Prevention. Initial therapy for tuberculosis in the era of multidrug resistance. MMWR 1993;42(No RR-7):1-8. 
66. Sumartojo $\mathrm{E}$. When tuberculosis treatment fails: a social behavioral account of patient adherence. Am Rev Respir Dis 1993;147:1311-20.

67. Morisky DE, Malotte CK, Choi $\mathrm{P}$, et al. A patient education program to improve adherence rates with anti-tuberculosis drug regimens. Health Educ Q 1990;17:253-67.

68. Cuneo WD, Snider DE Jr. Enhancing patient compliance with tuberculosis therapy. Clin Chest Med 1989;10:374-80.

69. Snider DE Jr, Hutton MD. Improving Patient Compliance in Tuberculosis Treatment Programs. Atlanta: Centers for Disease Control, 1989.

70. Weis SE, Slocum PC, Blais FX, et al. The effect of directly observed therapy on the rates of drug resistance and relapse in tuberculosis. $\mathrm{N}$ Engl J Med 1994;330:1179-84.

71. Cohn DL, Catlin BJ, Peterson KL, Judson FN, Sbarbaro JA. A 62-dose, 6-month therapy for pulmonary and extrapulmonary tuberculosis. Ann Intern Med 1990;112:407-15.

72. Hong Kong Chest Service/British Medical Research Council. Controlled trial of 2, 4, and 6 months of pyrazinamide in 6-month, three-times-weekly regimens for smear-positive pulmonary tuberculosis, including an assessment of a combined preparation of isoniazid, rifampin, and pyrazinamide: results at 30 months. Am Rev Respir Dis 1991;143:700-6.

73. Prabhaker R. Fully intermittent six month regimens for pulmonary tuberculosis in South India. Bull Int Union Tuberc 1987;62:21-3.

74. Anastasatu C, Bercea O, Corlan E. Pilot study of short course 3 plus 3 intermittent therapy in previously untreated smear positive tuberculosis. Bull Int Union Tuberc 1982;52:1-19.

75. Combs DL, O'Brien RJ, Geiter LJ. USPHS tuberculosis short-course chemotherapy trial 21: effectiveness, toxicity, and acceptability: the report of final results. Ann Intern Med 1990;112:397-406.
76. Iseman MD, Cohn DL, Sbarbaro JA. Directly observed treatment of tuberculosis: we can't afford not to try it. N Engl J Med 1993;328:576-8.

77. Brudney K, Dobkin J. Resurgent TB in New York City. Human immunodeficiency virus, homelessness and the decline of TB programs. Am Rev Respir Dis 1991;144:745-9.

78. Centers for Disease Control and Prevention. Improving adherence to antituberculosis therapy - South Carolina and New York. MMWR 1993;42:74.

79. Sbarbaro JA. Public health aspects of tuberculosis: supervision of therapy. Clin Chest Med 1980;1:253-63.

80. Curtis R, Friedman SR, Neaigus A, et al. Implications of directly observed therapy in tuberculosis control measures among IDUs. Public Health Rep 1994;109:319-27.

81. Davidson PT, Le HQ. Drug treatment of tuberculosis - 1992. Drugs 1992:43:651-73.

82. Pozsik CJ. Compliance with tuberculosis therapy. Med Clin North Am 1993;77:1289-301.

83. Bellin E. Failure of tuberculosis control: a prescription for change. JAMA 1994;271:708-9.

84. Health and Welfare Canada, Medical Services Branch. Medical Officer's Handbook Immigration Medical Service. 1992:1.1-4.15.

85. Guidelines for the investigation of individuals who were placed under surveillance for tuberculosis post-landing in Canada. Can Commun Dis Rep 1992;18-20:153-60.

86. Githui W, Nunn P, Juma E, et al. Cohort study of HIV-positive and HIV-negative tuberculosis, Nairobi, Kenya: comparison of bacteriological results. Tuber Lung Dis 1992;73:203-9.

87. Canadian Paediatric Society, Infectious Diseases and Immunization Committee. Short-course therapy for tuberculosis in infants and children. Can Med Assoc J 1994;150:1233-9. 


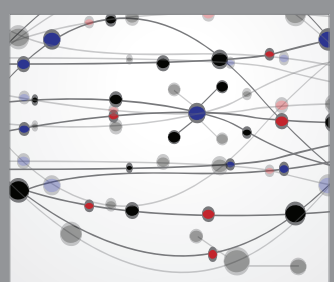

The Scientific World Journal
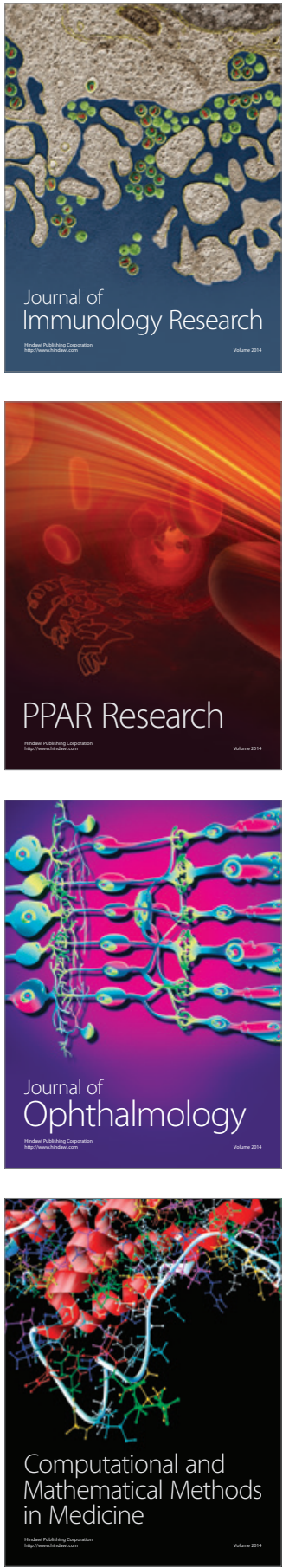

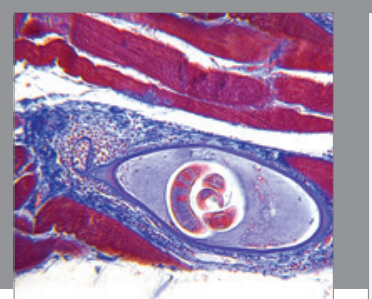

Gastroenterology Research and Practice

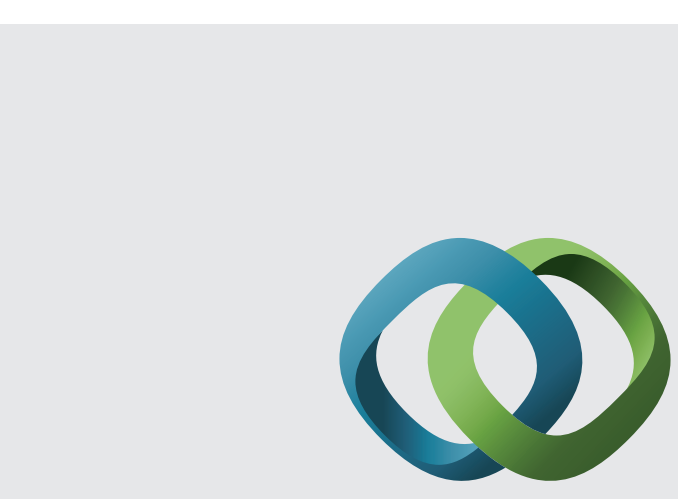

\section{Hindawi}

Submit your manuscripts at

http://www.hindawi.com
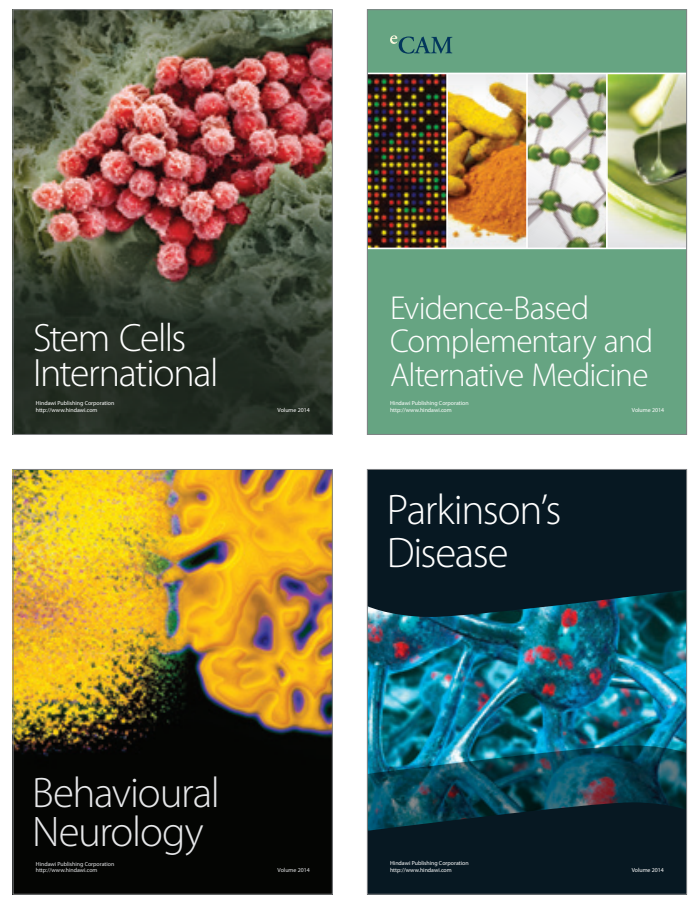
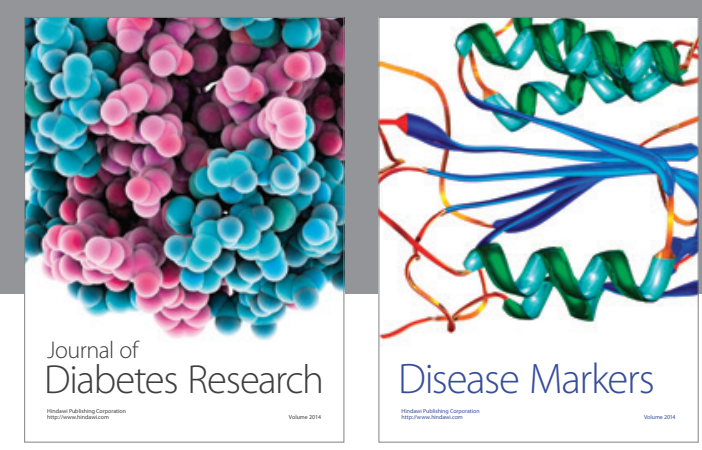

Disease Markers
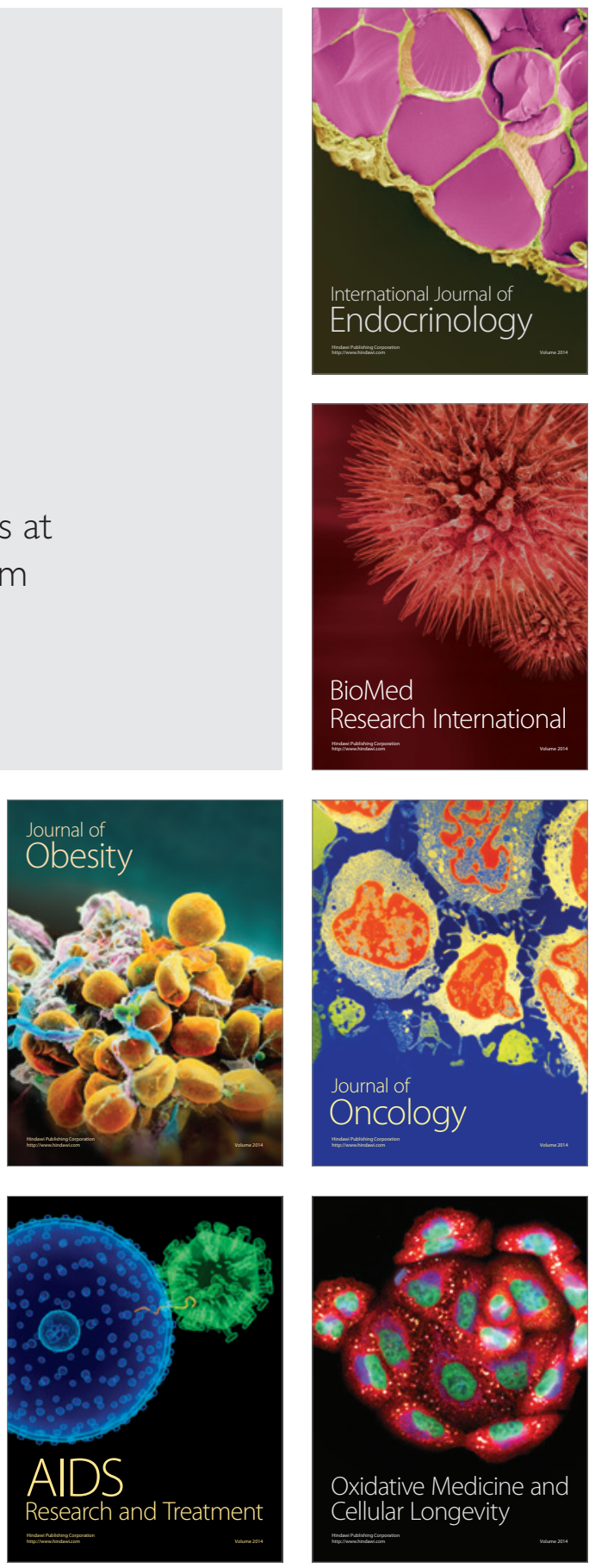